\title{
Inequality of Publishing Performance and International Collaboration in Physics
}

\author{
Mu-Hsuan Huang and Muh-Chyun Tang \\ Department of Library and Information Science, National Taiwan University, Taipei, Taiwan. \\ E-mail:mhhuang@ntu.edu.tw; mctang@ntu.edu.tw \\ Dar-Zen Chen \\ Department of Mechanical Engineering, National Taiwan University, Taipei, Taiwan. \\ E-mail:dzchen@ntu.edu.tw
}

\begin{abstract}
Using a database of 1.4 million papers indexed by Web of Science, we examined the global trends in publication inequality and international collaboration in physics. The publication output and citations received by authors hosted in each country were taken into account. Although inequality decreased over time, further progress toward equality has somewhat abated in recent years. The skewedness of the global distribution in publication output was shown to be correlated with article impact, that is, the inequality is more significant in articles of higher impact. It was also observed that, despite the trend toward more equalitarian distribution, scholarly participation in physics is still determined by a select group. Particularly noteworthy has been China's rapid growth in publication outputs and a gradual improvement in its impact. Finally, the data also suggested regional differences in scientific collaboration. A distinctively high concentration of transnational collaboration and publication performance was found among EU countries.
\end{abstract}

\section{Introduction}

The purpose of this study was to explore global trends in publication output and impact in physics over the past 20 years. Specifically, we were concerned with whether the degree of inequality, both in terms of publication output and impact, changes over time. It has long been observed that a premier league of nations dominates scientific output (Banerjee, Gupta, \& Garg, 2000; Bliziotis, Paraschakis, Vergidis, Karavasiou, \& Falagas, 2005; Braun, et al., 1994; Frame, 1991; Gibbs, 1995; King, 2004; May, 1997). In May 1997, for example, the top 15 most productive countries accounted for $81.3 \%$ of the world's papers from 1981

Received July 2, 2010; revised January 31, 2011; accepted January 31, 2011

(C) 2011 ASIS\&T • Published online 22 March 2011 in Wiley Online Library (wileyonlinelibrary.com). DOI: 10.1002/asi.21516 to 1994 in science, engineering, and medicine. The United States was found to be dominant, publishing around $35 \%$ of the world's science. However, it has also been shown that developing countries in Latin America and Asia have more recently started to close the gap in scientific performance (Bindé, 2005; Leydesdorff \& Zhou, 2005). It is, therefore, interesting to enquire as to whether the inequality of publishing performance has changed over time. Is there a trend toward less inequality in terms of publication output and impact? Are there new players joining those who are scientifically established? And what other long-term global publishing trends can be identified in physics? To address these questions, the present study mapped the characteristics of physics publications over the past 20 years. It was hoped that a longitudinal analysis could capture the dynamics of world participation in this fundamental branch of science.

\section{Methodology and Data Analysis}

The data were collected from Science Citation Index through the Web of Science (WoS, published by Thomson Reuters); a total of 336 journals in physics indexed by WoS in a 20-year period from 1989 to 2008 were included in our dataset, totaling 1,445,273 papers and 17,005,626 citations. To access the research performance of countries around the world, the nationalities of the authors' institutions were identified and country frequencies were tabulated, as authors' nationality data is not readily available. On average, each paper had 4.61 authors and received 11.77 citations. Some extreme values were observed in the data with the numbers of coauthors and citations ranging from 0 to 2,512, and 0 to 10,217 , respectively. A substantial portion of the papers resulted from transnational collaboration, with $22.79 \%$ of the papers containing authors from more than one country. The increasing average number of authors per publication 


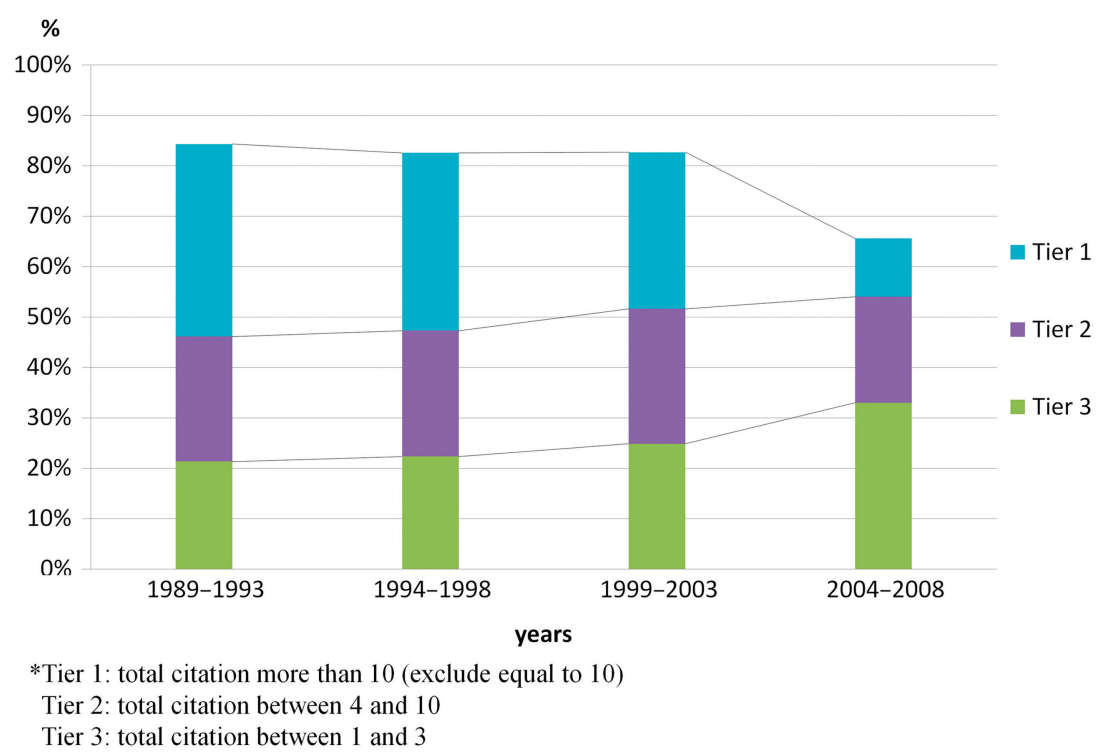

FIG. 1. Paper counts by intervals and citation tiers.

and the growth of international collaboration in the sciences pose a challenge as to how to attribute credit at the individual, institution and country levels (Cronin, Snyder, \& Atkins, 2001; Gauffriau, Larsen, Maye, Roulin-Perriard, \& Ins, 2008; Huang \& Lin. 2010; Kao, 2009; Pravdić \& Oluić-Vukovic, 1986, 1991). Although it has been shown that different counting methods produce different rankings in publication performance, a consensus has not yet emerged. The controversy mainly lies in how to attribute credit to the primary and secondary authorship and how to credit countries that produce multiple authors in the same paper.

In this study, we took the "whole counting" approach (Gauffriau, et al., 2008), in which all unique countries received a credit of one. In other words, a country received credit for a paper only once, even if there were additional addresses from that country in the paper. To maintain the shares of all the countries adding up to one hundred, the sum of the world's papers is defined as the sum of credits received by the countries. It was also recognized that by not distinguishing first and secondary authorship, developing countries were likely to be favored as they are presumably more likely to play a supporting role in transnational collaborations with advanced economies. Caution needs to be taken when cross-country comparisons are applied.

The citation counts of each paper were accumulated until the latest update on March 12, 2009, which left a relatively short citation window for the latest period. Without a sufficient citation window, the paper impact of the latest period is likely to be underestimated, considering the cited half-life among sub-fields in physics ranges from 3.7 years in nanoscience and nanotechnology at the lower end, to 8.9 years in acoustics at the high end. The underestimation might have the most impact on the tier 1 papers, as it generally takes longer for high impact papers to actualize (see Figure 1). Therefore, caution needs to be taken when cross-period comparisons are made from the data, particularly at the highest impact tier.

As a result, a total of 165 countries were found to have at least one author in the articles analyzed. To analyze the long-term trends, the data was broken down into four periods of 5 years: 1989-1993, 1994-1998, 1999-2003, and 20042008. Furthermore, the papers were divided into three impact tiers according to the citations they received: the tier 1 represents papers that received more than 10 citations, the tier 2 , 4 to 10 , and the tier 3,1 to 3 . This allowed us to investigate whether the inequality differed with the impact of the papers. The classification was made to ensure that each tier accounted for an equivalent share of papers (see Figure 1 for the distribution of papers of different tiers in the four time periods).

To compare the level of inequality over different periods and at different impact tiers, both the Gini coefficient and the Herfindahl-Hirschman Index (HHI) were applied as indexes to gauge the level of output and impact inequality (Evans, 2008; Lariviere, Gingras, \& Archambault, 2009). The Gini coefficient was developed originally to measure the degree of concentration (inequality) of a variable in a distribution of its elements. It compares the Lorenz curve of a ranked empirical distribution with the line of perfect equality. This line assumes that each element has the same contribution to the total summation of the values of a variable. The Gini coefficient ranges between 0 , where there is no concentration (perfect equality), and 1 , where there is total concentration (perfect inequality) (Atkinson, 1970).

$$
G=1-\sum_{i=0}^{N}\left(\sigma Y_{i-1}+\sigma Y_{i}\right)\left(\sigma X_{i-1}-\sigma X_{i}\right)
$$

where $\sigma \mathrm{X}$ and $\sigma \mathrm{Y}$ are cumulative percentages of country proportion and paper output in the same tier, and $\mathrm{N}$ is the number of countries. 


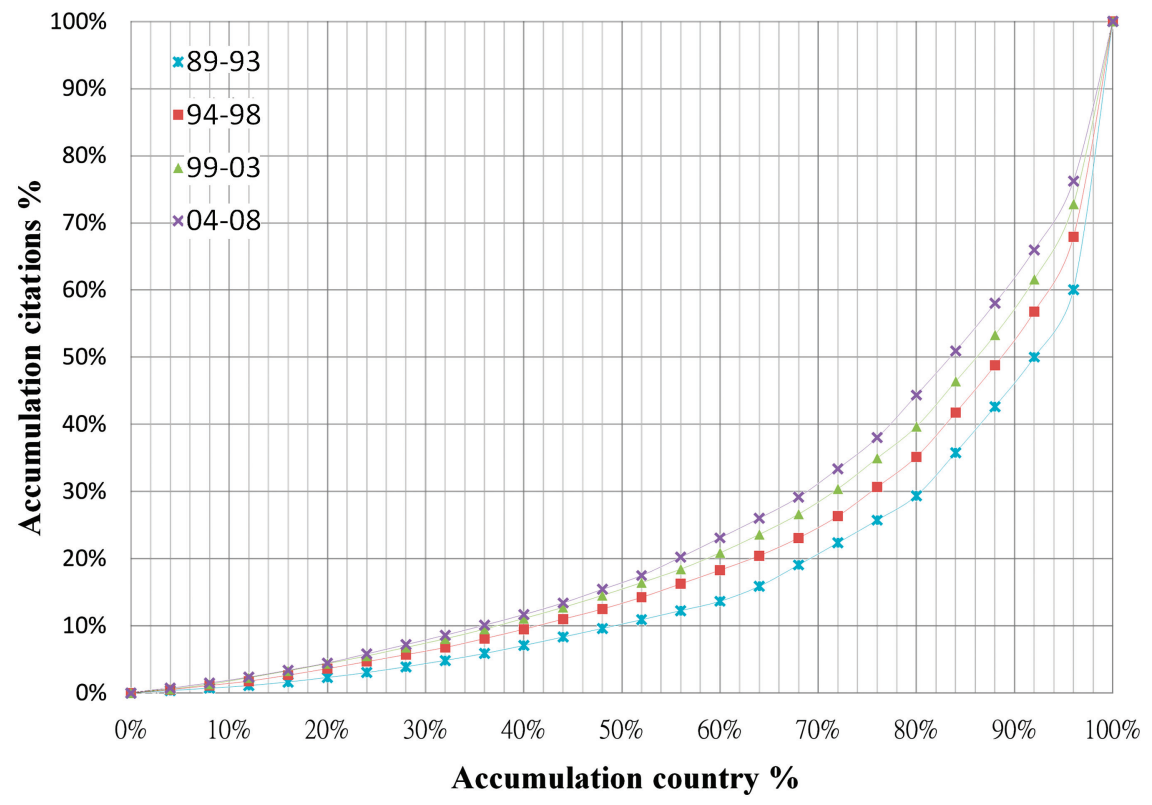

FIG. 2. Lorenz curves of the top 25 countries that received most citations over four intervals.

The HHI was originally a measure of the size of firms in relation to the industry and an indicator of the amount of competition among them.

$$
\begin{aligned}
H & =\sum_{i=1}^{N} s_{i}^{2} \\
H * & =\frac{(H-1) / N}{1-1 / N}
\end{aligned}
$$

HHI is computed as where $s_{i}$ is the market share of country $i$, and $N$ is the number of countries. Normalized Herfindahl-Hirschman index (N-HHI) is computed as where $\mathrm{N}$ is the number of countries, and $\mathrm{H}$ is the usual $\mathrm{HHI}$, as above. The normalization keeps the number ranges from 0 to 1 .

Relative citation impact (RCI) was used measure (Braun, Glanzel, \& Schubert, 1985; Kumari, 2009; May, 1997) to assess the relative impact of the papers produced by a country (Kumari, 2009; May, 1997; Thomson Reuters, 2010). RCI is attained by dividing a nation's share of world citations by its share of world publications. A value of RCI above 1 indicates a country's research output has a higher than average impact.

\section{Results}

\section{Publication Performance}

We first looked into the distribution of citations received in physics among the elite group, including 25 countries received the most citations. Figure 2 shows the Lorenz curves of citations received of elite group in physics in four time periods: 1989-1993, 1994-1998, 1999-2003, and 2004-2008. The Lorenz curve plots accumulated percentage of countries (the $\mathrm{X}$-axis) by accumulated percentage (the Y-axis) of citations among the 25 most-cited countries in each period. The diagram shows a steady decline in inequality as measured by the Gini index over time, with the 2004-2008 interval recording the lowest Gini-index and its Lorenz curve being the closest to the line of equality. In other words, more countries were gradually required to account for the same percentage of citations received, which indicated growing competition within the most prolific counties.

Notice that the declining inequality is most dramatic in the 1989-1993 interval, followed by 1994-1998, with the pace toward less inequality slowing down in later periods. The same analysis was then applied to counties that fall outside of the top 25 . The same trend toward less inequality was observed in the top 50, 75, and 100 countries that received most citations (Figure 3). This is probably to be expected given how citations are heavily concentrated in a small percentage of all nations. The top 25 countries already account for $94.04 \%$ of all citations, resulting in little impact by the inclusion of more countries on any certain time interval's relative inequality position. Similar analyses were conducted using N-HHI (Larivière, Gingras, \& Archambault, 2009), which calibrated the findings (Figure 4).

We next looked into whether the same trend toward less inequality also occurred in publication output. Again, the analyses were done at the top $25,50,75$, and 100 countries levels, and the same trend toward less inequality manifested itself at every level. The observed trend toward equality could be incomplete, however, without considering the impact dimension of scholarly performance. As scholars compete for publication impact venues that receive higher citations, one suspects that the competition is much more intense in tier 1 papers and more difficult for authors in developing countries to break into. It is therefore reasonable to speculate that the level of inequality among world countries might increase with the impact of the papers. To investigate whether 


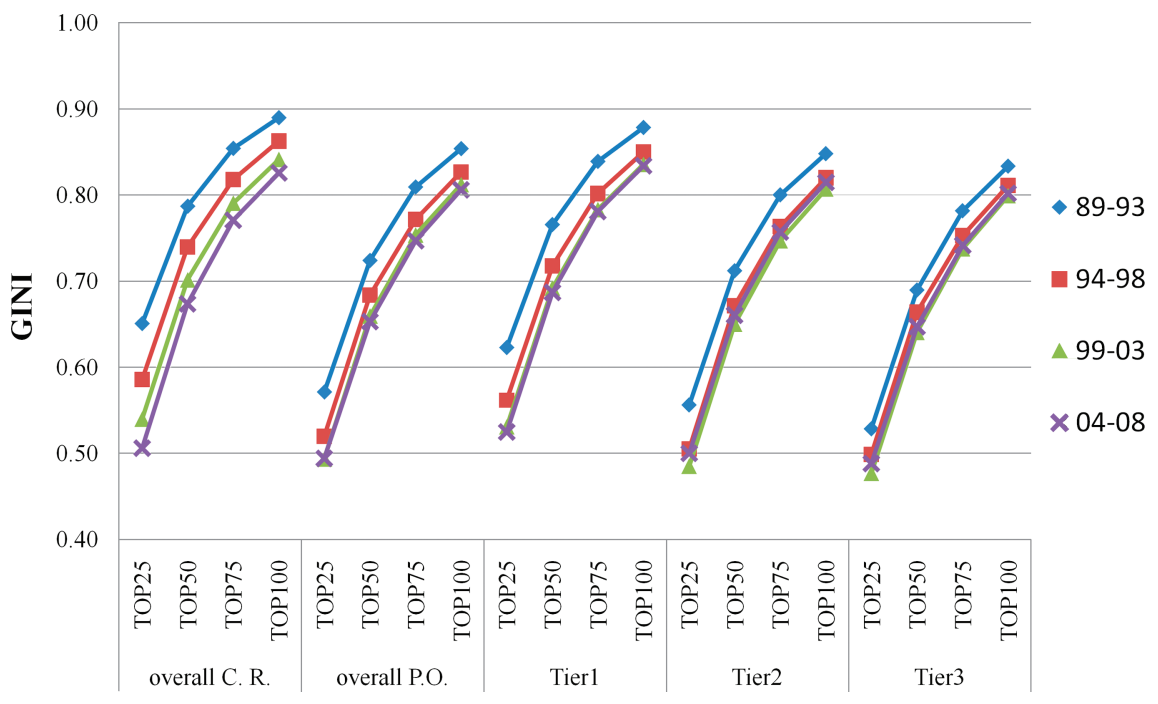

*C.R. means citation received; where P.O. means publication output.

FIG. 3. GINI index by time intervals and impact tiers.

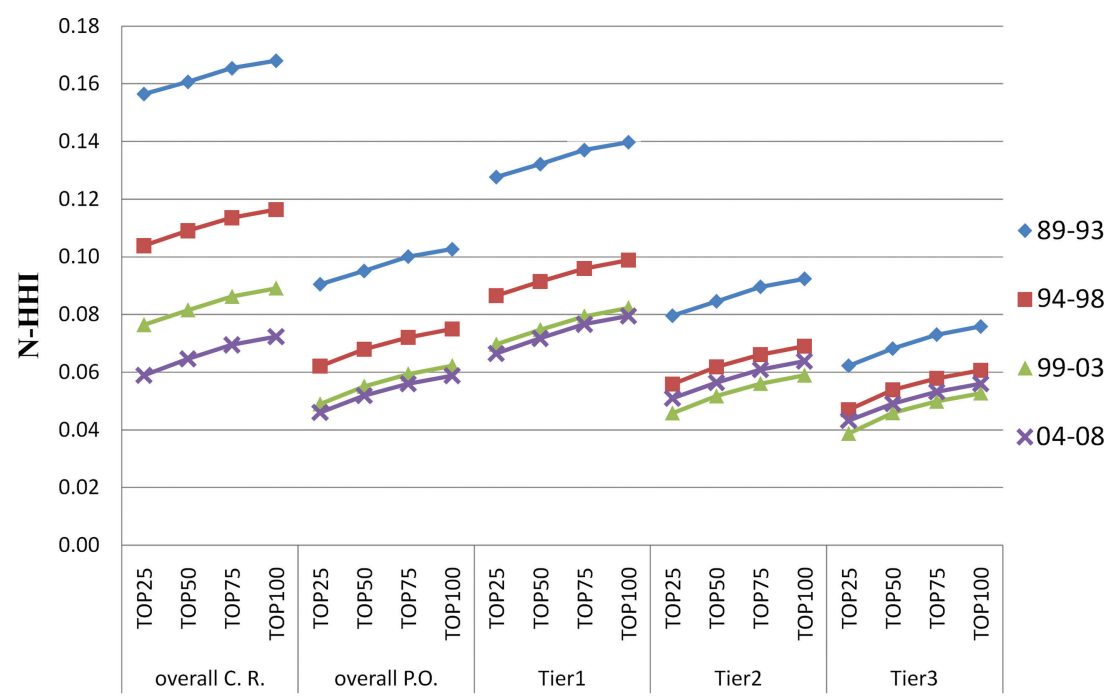

*C.R. means citation received; where P.O. means publication output.

FIG. 4. N-HHI by time intervals and impact tiers.

the degree of inequality differs with the impact of the papers, further analysis was done by categorizing the publications by three tiers of impact: those received 1 to 3 (tier 3), 4 to 10 (tier 2), and more than 10 citations (tier 1). It was shown that inequality increased with the impact of papers, with the tier 1 papers (citations greater than 10) having the highest degree of inequality, followed by tier 2 and tier 3 papers. Notice that the decrease of inequality was most conspicuous in the 1989-1993 to 1994-1998 periods, and has tapered off since (Figures 3 and 4).

\section{Barrier to Entry Into the Premier League}

It is not clear whether the trend toward less inequality in general took place among the same more economically advanced countries, or if more countries have joined their ranks. We next investigated the degree to which the memberships of countries with the highest scholarly participation fluctuated over time. To gauge the consistency of the constitution of countries that garnered the most publications over the four time periods, we used Jaccard's coefficient. To calculate the coefficient for each tier, we counted the number of countries that were in the top 25 most productive country list in each time interval, then we divided it by the number of all countries entering the top 25 list in any of four intervals. The results show that the constitution of the countries is relatively stable at different levels of performance and over time. The top 25 and top 50 countries that produced the highest impact papers (i.e., received $>10$ citations) have much higher degrees of concentration (0.815 in the Top 25; 0.786 


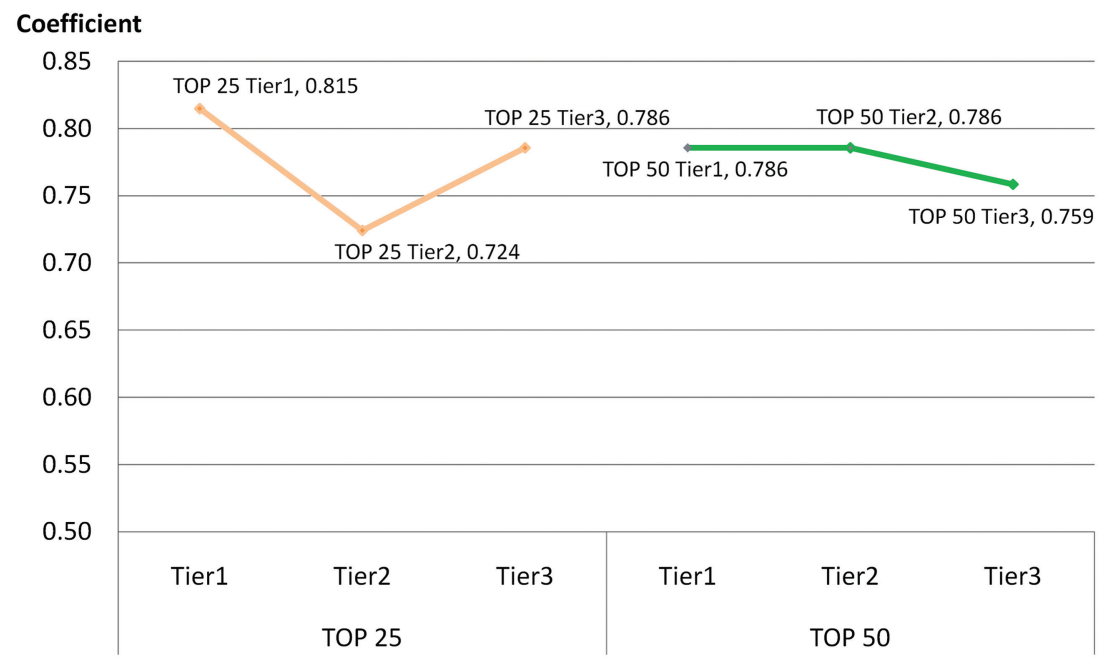

FIG. 5. Similarity of country memberships in elite group by Jaccard's coefficient.

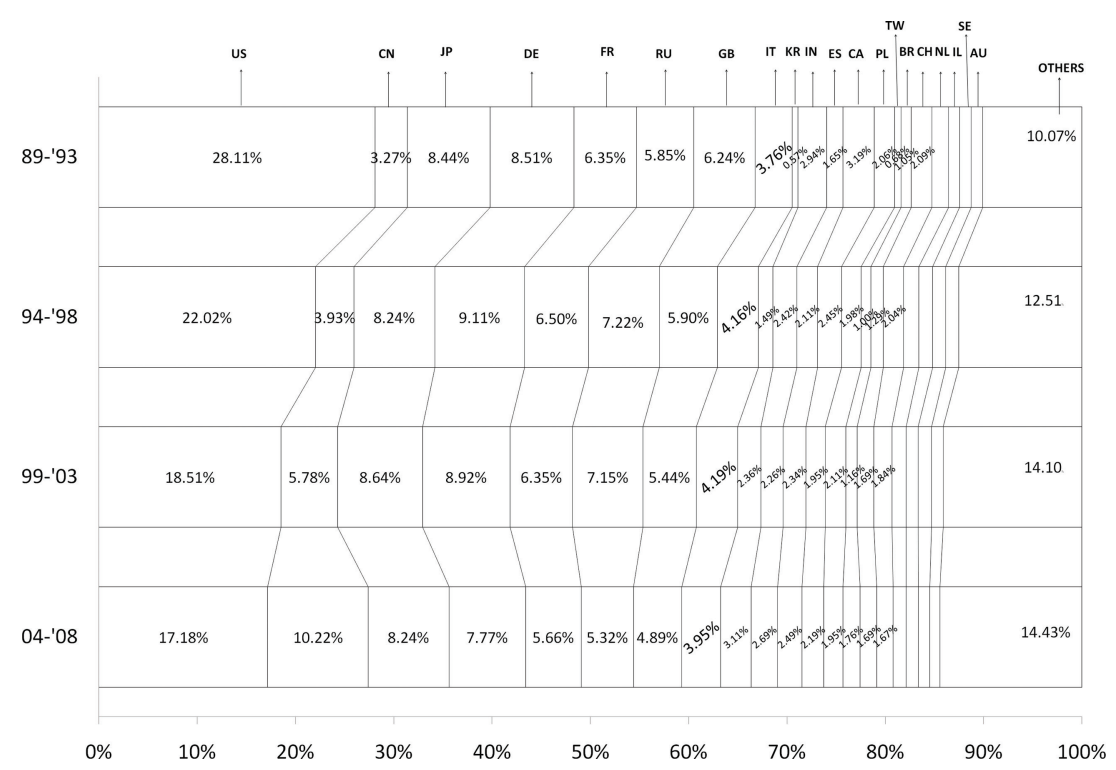

FIG. 6. Shares of publications over four time intervals.

in the Top 50), compared to the tier $2(0.724 ; 0.786)$ and tier 3 $(0.786 ; 0.759)$ papers. And the coefficient of tier 2 with more countries entering the all countries list is higher than tier 3 . In other words, the countries that produced papers with the highest impact in the most competitive sector formed the tightest knit group. Coupled with our previous finding of the trend toward less inequality, the fact that the constitution of the high performance countries varies little over time suggests that the redistribution results mostly from internal competition, rather than from new countries gaining admittance. (Figure 5 Jaccard's coefficient of county constitution)

We focus our analysis on the top 25 countries as they were shown to account for more than $90 \%$ of the total publication. Figure 6 shows the fluctuations in countries' share of publication output over the four time periods. The most noticeable trends are the continued growth of China, up from 3.27 to
$10.22 \%$, along with the dip of the dominance of the United States, from 28.11 to $17.18 \%$. China's growth in publication output has not, however, translated proportionally into its impact. Figure 7 shows the shares of citations received in the same time periods. While declining slightly, the United States remains the country with the highest impact, followed by Germany, Japan, and China. China still enjoys the most dramatic improvement in the past 20 years. It is worth noting that the contributions made by countries outside the top 25 has increased slightly over the years in publication output (from $7.88 \%$ to $10.30 \%$ ), and to a greater degree, in citations received (from $3.97 \%$ to $8.22 \%$ ).

Figure 8 shows percentile change of countries' RCI between the earliest and latest intervals. Countries are marked differently from four regions (Europe, East Asia, North America and Latin America) for comparisons in the figure. 


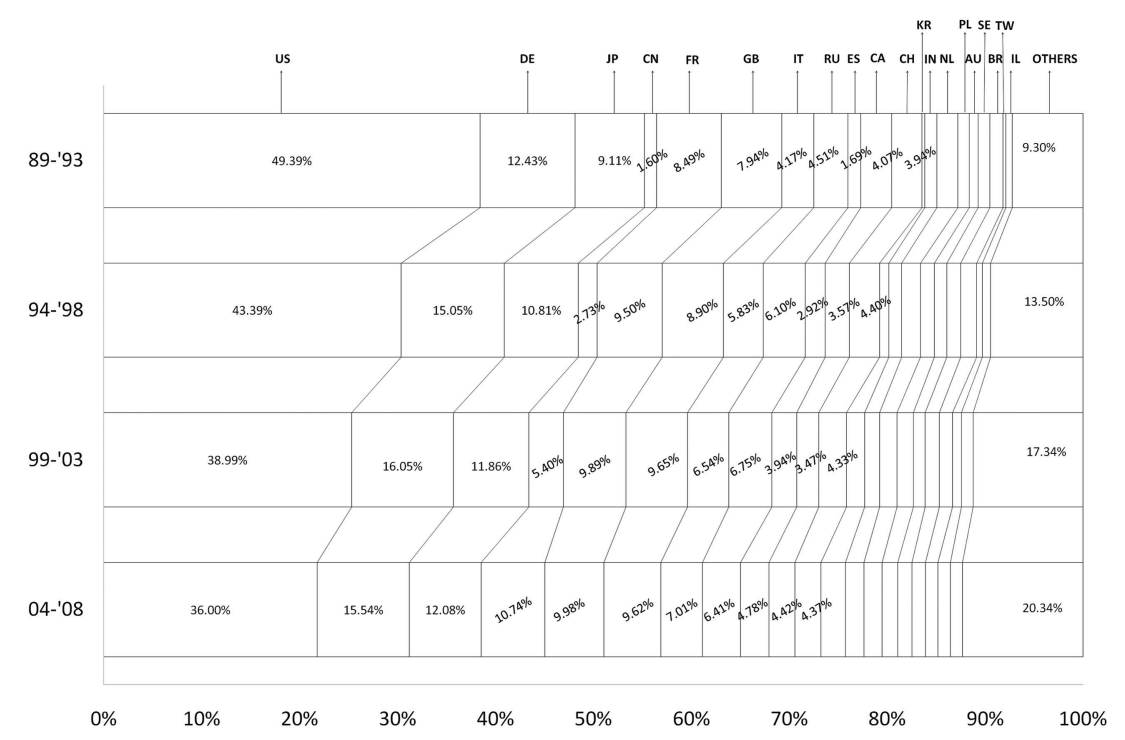

FIG. 7. Shares of citations received over four time intervals.

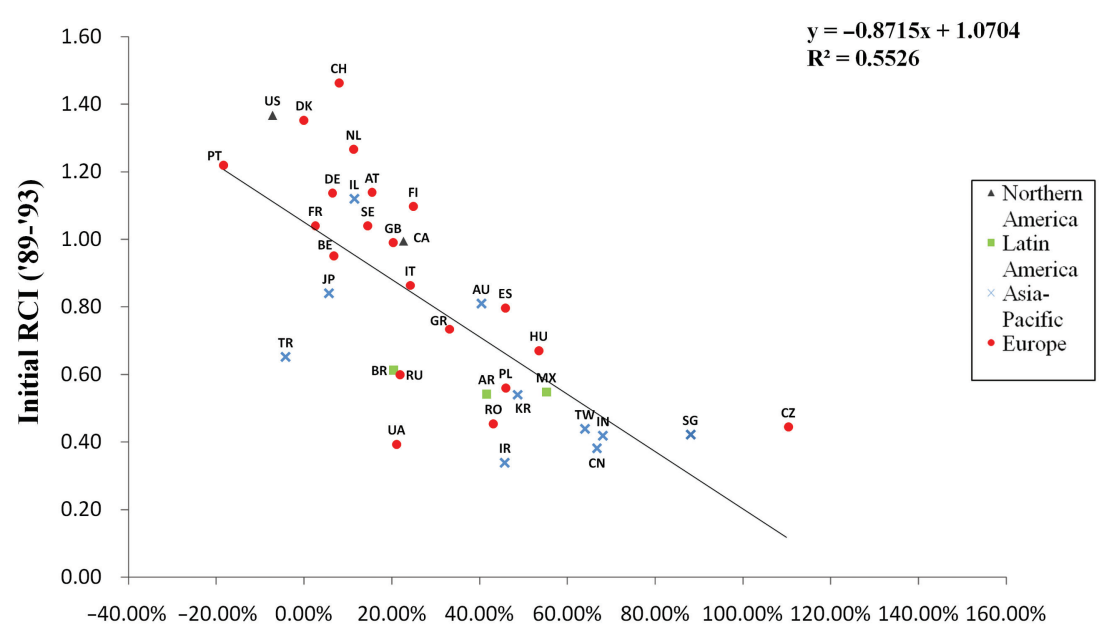

Changed over time in RCI (\%)

$\triangle \mathrm{US} \triangle \mathrm{CA}=\mathrm{BR}=\mathrm{MX}=\mathrm{AR} \times \mathrm{CN} \times \mathrm{JP} \times \mathrm{KR} \times \mathrm{IN} \times \mathrm{TW} \times \mathrm{AU} \times \mathrm{IL} \times \mathrm{SG} \times \mathrm{TR} \times \mathrm{IR} \bullet \mathrm{DE} \bullet \mathrm{FR} \bullet \mathrm{RU}$

$\bullet \mathrm{GB} \bullet \mathrm{IT} \bullet \mathrm{ES} \bullet \mathrm{PL} \bullet \mathrm{CH} \bullet \mathrm{NL} \bullet \mathrm{SE} \bullet \mathrm{BE} \bullet \mathrm{UA} \bullet \mathrm{AT} \bullet \mathrm{CZ} \bullet \mathrm{GR} \bullet \mathrm{DK} \bullet \mathrm{PT} \bullet \mathrm{HU} \bullet \mathrm{RO} \bullet \mathrm{FI}$

FIG. 8. Initial RCI and percentage changes of the countries.

The chart indicates an interesting regional difference in publication performance as countries of the same region tend to cluster together. Among the economically advanced countries, Finland, Australia, Italy, Canada, and Spain have achieved the most considerable growth in RCI. Switzerland has the highest impact in both time periods, followed by the United States. The growth of Switzerland and Netherlands is especially remarkable because they were able to maintain qualitative improvement, even from a higher base rate. More substantial growth can be found in the newly industrialized countries starting from a lower base rate: The Czech Republic has the most impressive growth, followed by East Asian countries such as Korea, Singapore, India, China, and Taiwan. Countries in Latin America such as Brazil, Argentina, and Mexico are also shown to make great strides, making substantial gains in their RCI. In the Middle East, Iran has likewise proven noteworthy in terms of its output and impact. Figure 9 gives an overview of the changes in the impact and output of physics publications of selected countries over the four time periods.

\section{Transnational Coauthorship}

The past 20 years also witnessed a steady growth of international coauthorship (Boekholt, Edler, Cunningham, \& Flanagan, 2009; Leydesdorff \& Wagner, 2008). The percentage of papers by international coauthorship increased from $15.30 \%$ to $25.43 \%$. This growth pattern mirrors that of the trend toward less inequality, with an earlier, more salient period of growth slowing down in recent years. One might wonder whether the lessening of performance inequality reported previously is mainly due to the growth of 


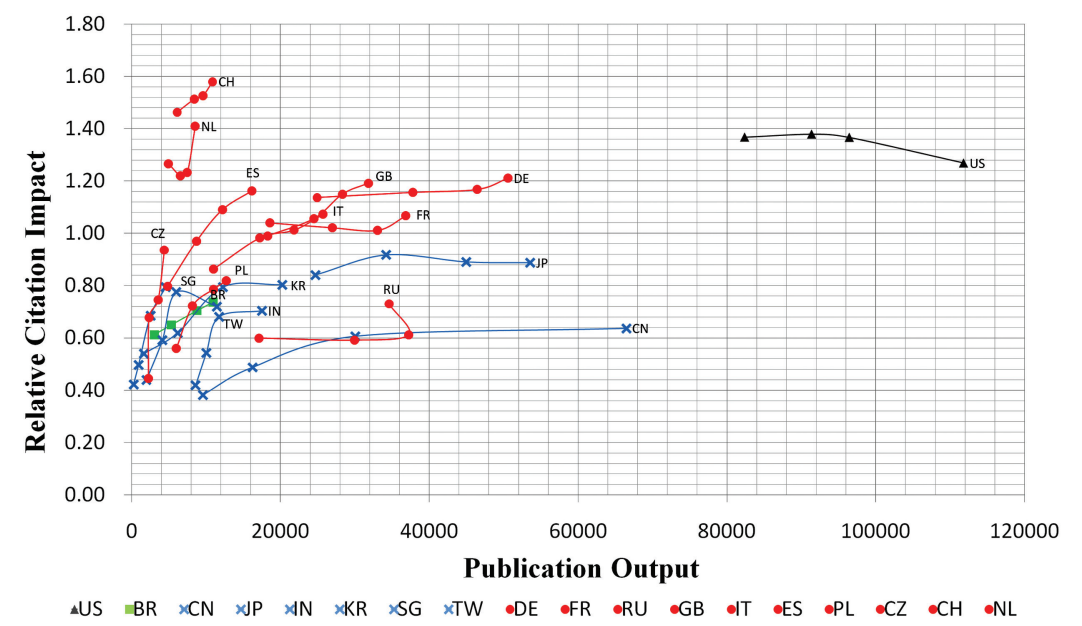

$* \mathrm{RCli}=\mathrm{ci} / \mathrm{pi}=(\mathrm{Ci} / \mathrm{C}) /(\mathrm{Pi} / \mathrm{P})$ For country $\mathrm{i}$, let total papers be $\mathrm{Pi}$ and citations $\mathrm{Ci}$. The share of the world's papers is then $\mathrm{pi}=\mathrm{Pi} / \mathrm{P}$, where $\mathrm{P}=\mathrm{Pj}$ is the worlds' total number of papers. Similarly, citation share is ci $=\mathrm{Ci} / \mathrm{C}$, with $\mathrm{C}=\mathrm{Cj}$. Hence $\mathrm{RCIi}=\mathrm{ci} / \mathrm{pi}=(\mathrm{Ci} / \mathrm{Pi})(\mathrm{P} / \mathrm{C})$. That is, for country $\mathrm{i}$, the average number of citations per paper, $\mathrm{Ci} / \mathrm{Pi}$, is RCli multiplied by the ratio of all citations.

FIG. 9. Changes of publications' output and impact as measured by RCI.

international coauthorship. Admittedly, our analyses of the inequality trends are to some extent confounded by the large and growing portion of papers involving transnational collaboration, where, as in the cases of international coauthorship, all hosting countries receive equal credit in our performance measures. However, the trend toward less inequality cannot be solely attributed to international collaboration alone (Leta \& Chaimovich, 2002). Our data revealed an interesting relationship between region-specific collaboration practice and resulting publication impact that has not received much attention before.

Table 1 shows percentages of international papers of nations' total publications ranked in ascending order in the past 20 years. It is interesting to see that many East Asian countries have a relatively low degree of transnational collaboration: Japan, arguably one of the most scientifically established countries, has the lowest degree of international coauthorship in the past 20 years. Figure 10 shows the relationship between countries' RCI and percentages of international papers of nations' total publications in the 2004 2008 interval, which suggests a regional difference in the relationship between international collaboration and publishing impact. It is interesting to see that many other East Asian countries have a relatively low degree of transnational collaboration, with China being the second lowest.

China, South Korea, and Taiwan, countries that have each significantly improved their publication performance, are similarly not renowned for extensive international collaboration. China's percentage of international papers actually dropped from $23.25 \%$ in $1999-2003$ to $20.15 \%$ in 2004 2008 , despite a tremendous growth in publication output in the same period. In fact, the decline of international papers is more likely the byproduct of a tremendous growth in China's publication output, rather than any lack of international effort per se. Iran's international collaboration declined, even though both the output and impact of its publications had significantly improved over the years.

The opposite is true of Switzerland, which has the second highest international paper percentage $(71.81 \%)$ and the highest RCI (1.58). In this case there was a slight drop in its share of world publication. Other countries that have a very high density of international papers in their total output in the 2004-2008 period also have very high RCI, most notably European Union (EU) members like Netherlands, Austria, Demark, Finland, and Sweden.

A simple linear line of best fit and its correlation coefficient present in Figure 10. It shows that EU countries tend to cluster around the upper-right corner of the linear line of best fit between transnational coauthorship and RCI, while the Eastern Asian countries gathering around the bottom-left and Latin American countries in the middle.

\section{Discussion and Implications}

Using data obtained from WoS, we were able to study the performance trends in physics publication over the past 20 years. Gini coefficient and HHI, two common indexes for distributional inequality, were used to assess the state of world inequality in publication output and impact. The longitudinal approach adopted in the present study allows us to identify the trends toward less inequality in publication output and global impacts in physics (Larivière, et al., 2009). There is less global inequality in publication and impact performance gradually. The most rapid change was discernible in the early 90 s, with this in turn slowing markedly in recent years. Perhaps more noticeably among the findings was that, despite the slight progress made by less economically advanced countries, it is still difficult for them to contribute significantly to the global literature in physics. The inequality is more salient 
TABLE 1. Percentage of international coauthorship by countries.

\begin{tabular}{|c|c|c|c|c|c|c|}
\hline Country & & 89-08 & $89-93$ & $94-98$ & $99-03$ & 04-08 \\
\hline Japan & JP & $27.31 \%$ & $14.01 \%$ & $21.36 \%$ & $27.79 \%$ & $29.45 \%$ \\
\hline India & IN & $27.85 \%$ & $13.26 \%$ & $20.59 \%$ & $28.92 \%$ & $29.26 \%$ \\
\hline Peoples R China & $\mathrm{CN}$ & $31.37 \%$ & $17.86 \%$ & $21.32 \%$ & $23.25 \%$ & $20.15 \%$ \\
\hline USA & US & $31.61 \%$ & $20.26 \%$ & $29.51 \%$ & $38.40 \%$ & $39.54 \%$ \\
\hline Taiwan & TW & $33.66 \%$ & $14.04 \%$ & $23.40 \%$ & $31.24 \%$ & $26.44 \%$ \\
\hline Russia & RU & $36.23 \%$ & $24.89 \%$ & $37.45 \%$ & $43.38 \%$ & $47.02 \%$ \\
\hline South Korea & KR & $38.72 \%$ & $27.22 \%$ & $29.61 \%$ & $32.28 \%$ & $31.93 \%$ \\
\hline Turkey & TR & $39.42 \%$ & $30.82 \%$ & $34.31 \%$ & $34.89 \%$ & $28.95 \%$ \\
\hline Brazil & $\mathrm{BR}$ & $40.86 \%$ & $37.13 \%$ & $45.11 \%$ & $43.23 \%$ & $41.41 \%$ \\
\hline Australia & $\mathrm{AU}$ & $41.02 \%$ & $25.04 \%$ & $36.48 \%$ & $50.25 \%$ & $55.71 \%$ \\
\hline England & GB & $41.23 \%$ & $31.84 \%$ & $43.55 \%$ & $52.80 \%$ & $57.96 \%$ \\
\hline Argentina & $\mathrm{AR}$ & $41.74 \%$ & $35.71 \%$ & $41.25 \%$ & $50.87 \%$ & $57.08 \%$ \\
\hline Mexico & MX & $41.82 \%$ & $33.47 \%$ & $42.85 \%$ & $47.23 \%$ & $46.43 \%$ \\
\hline Canada & $\mathrm{CA}$ & $42.35 \%$ & $36.01 \%$ & $45.99 \%$ & $55.44 \%$ & $56.87 \%$ \\
\hline Israel & $\mathrm{IL}$ & $42.61 \%$ & $46.17 \%$ & $49.62 \%$ & $53.54 \%$ & $54.06 \%$ \\
\hline Ukraine & UA & $43.43 \%$ & $33.80 \%$ & $40.14 \%$ & $53.13 \%$ & $54.56 \%$ \\
\hline France & FR & $43.80 \%$ & $39.67 \%$ & $47.53 \%$ & $56.19 \%$ & $61.08 \%$ \\
\hline Germany & $\mathrm{DE}$ & $43.91 \%$ & $37.96 \%$ & $48.18 \%$ & $57.67 \%$ & $61.28 \%$ \\
\hline Italy & IT & $44.22 \%$ & $43.00 \%$ & $51.01 \%$ & $53.73 \%$ & $56.17 \%$ \\
\hline Netherlands & NL & $44.70 \%$ & $39.10 \%$ & $51.88 \%$ & $60.17 \%$ & $64.43 \%$ \\
\hline Poland & PL & $44.93 \%$ & $41.01 \%$ & $55.54 \%$ & $58.08 \%$ & $56.37 \%$ \\
\hline Singapore & SG & $46.32 \%$ & $19.13 \%$ & $30.16 \%$ & $35.50 \%$ & $44.17 \%$ \\
\hline Spain & ES & $47.36 \%$ & $44.19 \%$ & $50.00 \%$ & $56.26 \%$ & $60.66 \%$ \\
\hline Iran & IR & $47.37 \%$ & $35.23 \%$ & $32.12 \%$ & $31.67 \%$ & $25.57 \%$ \\
\hline Sweden & SE & $47.38 \%$ & $48.09 \%$ & $59.70 \%$ & $63.61 \%$ & $66.70 \%$ \\
\hline Denmark & DK & $47.77 \%$ & $60.46 \%$ & $66.64 \%$ & $69.32 \%$ & $66.08 \%$ \\
\hline Greece & GR & $48.05 \%$ & $46.11 \%$ & $61.25 \%$ & $61.17 \%$ & $60.48 \%$ \\
\hline Czech Republic & $\mathrm{CZ}$ & $48.49 \%$ & $37.18 \%$ & $63.64 \%$ & $67.96 \%$ & $66.69 \%$ \\
\hline Romania & $\mathrm{RO}$ & $48.57 \%$ & $41.00 \%$ & $54.70 \%$ & $63.72 \%$ & $64.09 \%$ \\
\hline Switzerland & $\mathrm{CH}$ & $48.97 \%$ & $56.86 \%$ & $62.17 \%$ & $69.22 \%$ & $71.81 \%$ \\
\hline Finland & FI & $49.05 \%$ & $51.69 \%$ & $61.78 \%$ & $65.00 \%$ & $63.78 \%$ \\
\hline Belgium & $\mathrm{BE}$ & $49.08 \%$ & $48.70 \%$ & $59.41 \%$ & $66.77 \%$ & $68.96 \%$ \\
\hline Hungary & $\mathrm{HU}$ & $50.44 \%$ & $55.74 \%$ & $68.51 \%$ & $73.61 \%$ & $69.83 \%$ \\
\hline Austria & $\mathrm{AT}$ & $50.52 \%$ & $51.86 \%$ & $63.27 \%$ & $70.44 \%$ & $72.02 \%$ \\
\hline Portugal & PT & $53.97 \%$ & $54.44 \%$ & $63.83 \%$ & $64.65 \%$ & $66.48 \%$ \\
\hline
\end{tabular}

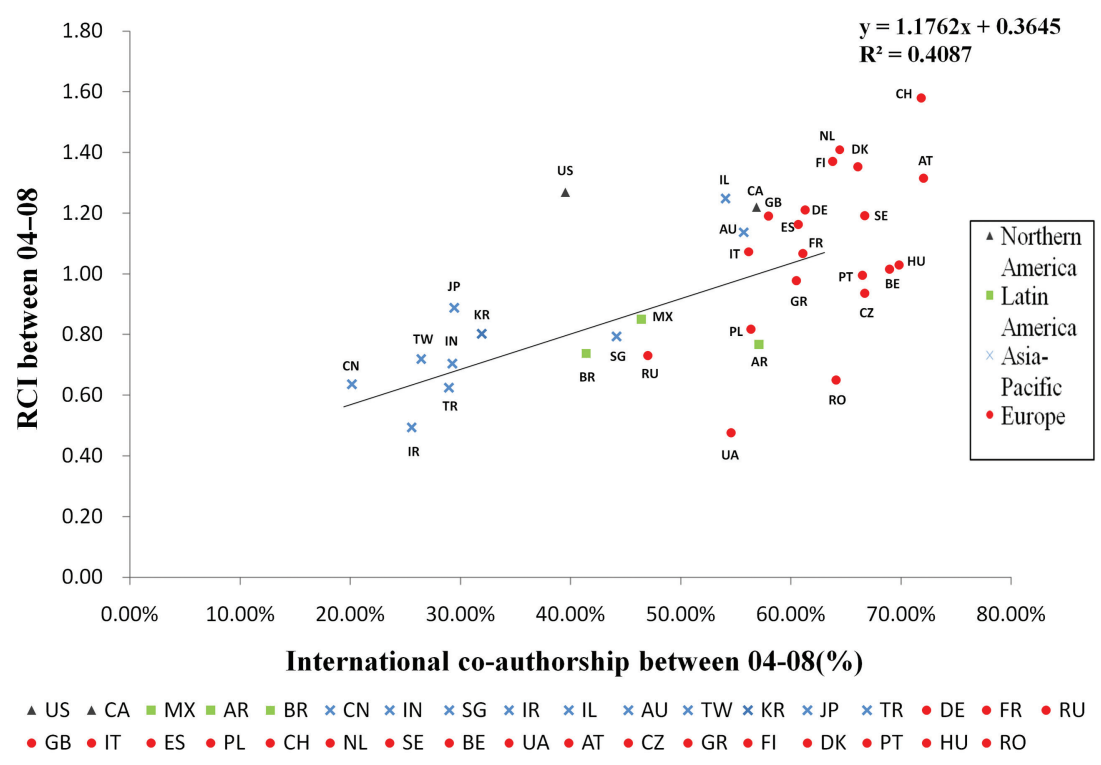

FIG. 10. Plot of RCI and international coauthorship between 04-08. 
in publication impact than output, at least for journals indexed by WoS.

Among the top 25 most established countries, the most noticeable phenomenon was China's dramatic growth in publication outputs, in tandem with a gradual improvement in the impact of its publications. The rapid growth of China in the physics literature echoes the previous findings of Guan and Ma (2004) in computer science, Kumari (2009) in synthetic organic chemistry, and Leydesdorff and Zhou (2005) in the broader sciences. This might not come as a surprise considering the economic growth enjoyed by China in the past decades and the concerted efforts by the government to promote scientific progress (Fan \& Watanabe, 2006; Forster, 2006; Leydesdorff \& Zhou, 2005).

China's growth in publication output is especially noteworthy considering its relatively low percentage of international papers. The other interesting phenomenon is the globalization of scientific endeavors. The past 20 years has seen a gradual increase in publications produced by international collaboration. Even though it remains difficult to draw any concrete conclusions regarding the relationships between international collaboration and publication output and impact (Glänzel, 2001; Inzelt, Schubert, \& Schubert, 2009; Schmoch \& Schubert, 2008; Van Raan, 1998), our analysis seems to suggest a correlation between transnational cooperation and research impact.

A strong presence of transnational collaboration and very high impact were observed in papers originated from EU countries, which is likely to result from the large cooperative networks created around the "big science" European facilities. The high publication impact enjoyed by the EU countries has important policy implications for countries that aspire to raise their research profile. Judging by the very active transnational collaboration networks in the EU countries and their impressive research performance (Glänzel, 2001; Leydesdorff, 2000; Leydesdorff \& Wagner, 2008; Narin, Stevens, \& Whitlow, 1991; Narin \& Whitlow, 1990), one wonders if increasing involvement in international collaboration will deepen the already notable achievements made by some of the East Asian countries, namely, Japan, South Korea, China, and Taiwan (Kim, 2001). It is worth noting that Singapore, which enjoys the greatest RCI growth in this region (Figure 8), is also the most active in transnational collaboration. A cross-regional study of transnational collaboration (Filippo, Morillo, \& Fernández, 2008; Glänzel, 2001; Glänzel, Schubert, \& Czerwon, 1999; Leta, \& Chaimovich, 2002) might tell us more about its potential influence on publication performance. For example, a comparison of the scientific collaboration patterns between those in EU and East Asian countries would have the makings of a fruitful exercise.

One also wonders whether the relationships between international collaboration and research performance among physicists can be carried over into other disciplines as one can imagine that there might be discipline-specific research and publication practices that manifest in authors' publishing and citing behaviors (Frederiksen, 2004; Glänzel, \& Schubert, 2001; New, 2001; Qin, Lancaster, \& Allen, 1997).
Even within the domain of physics, researchers' collaboration and publication practices might vary from one specialty to the other. An extreme example will be high-energy physics (HEP), where large numbers of transnational coauthorship are often observed, reflecting HEP as a highly collaborative field where teams from all over the world are involved in large-scale experiments run on sophisticated infrastructure, such as Large Hadron Collide (LHC) at European Center for Nuclear Research (CERN; Hofer, Mckee, Birnholtz, \& Avery, 2008). Further work needs to be done to gauge the impact of such extreme cases on the overall bibliometric data.

The heterogeneity in scholarly practice also points to the need to elicit insights from practitioners when interpreting bibliometric data. A qualitative study of the nature and typology of distributed collaboration would reveal much needed insights beyond the coauthorship data (Olson, Zimmerman, \& Bos, 2008). A cross-disciplinary comparison that includes both scientometric and qualitative data could be employed to determine if there are domain specific practices that might exert an influence on international collaboration and publication impacts of world countries.

\section{Acknowledgment}

We thank the anonymous reviewers and the editor for their valuable comments and suggestions.

\section{References}

Atkinson, A.B. (1970). On the measurement of inequality. Journal of Economic Theory, 2(3), 244-263.

Banerjee, P., Gupta, B., \& Garg, K. (2000). Patent statistics as indicators of competition an analysis of patenting in biotechnology. Scientometrics, 47(1), 95-116.

Bindé, J. (2005). Towards knowledge societies: UNESCO world report Paris: UNESCO.

Bliziotis, I., Paraschakis, K., Vergidis, P., Karavasiou, A., \& Falagas, M. (2005). Worldwide trends in quantity and impact of published articles in the field of infectious diseases. BMC Infectious Diseases, 5(1), 16.

Boekholt, P., Edler, J., Cunningham, P., \& Flanagan, K. (2009). Drivers of International collaboration in research. Retrieved from http:// www.eurosfaire.prd.fr/7pc/doc/1266832886_drivers_of_international_ cooperation_in_research.pdf

Braun, T., Glanzel, W., \& Schubert, A. (1985). Scientometrici indicators: A 32 country comparative evaluation of publishing performance and citation impact. Singapore: World Scientific Publishing Co.

Braun, J., Laitko, S., Treharne, J., Eggens, U., Wu, P., Distler, A., \& Sieper, J. (1994). Chlamydia pneumoniae-A new causative agent of reactive arthritis and undifferentiated oligoarthritis. Annals of the Rheumatic Diseases, 53(2), 100-105.

Cronin, B., Snyder, H., \& Atkins, H. (1997). Comparative citation rankings of authors in monographic and journal literature: a study of sociology. Journal of Documentation, 53(3), 263-273.

Evans, J.A. (2008). Electronic publication and the narrowing of science and scholarship. Science, 321(5887), 395-399.

Fan, P., \& Watanabe, C. (2006). Promoting industrial development through technology policy: Lessons from Japan and China. Technology in Society, 28(3), 303-320.

Filippo, D.D., Morillo, F., \& Fernández, M.T. (2008). Indicators of scientific collaboration between CSIC and Latin America through internationa databases. Revista Espanola de Documentacion Cientifica, 31(1), 18.

Forster, C.J. (2006). China's secret weapon? Science policy and global power. London: Foreign Policy Centre (FPC). 
Frame, J. (1991). Modelling national technological capacity with patent indicators. Scientometrics, 22(3), 327-339.

Frederiksen, L.F. (2004). Disciplinary determinants of bibliometric impact in Danish industrial research: Collaboration and visibility. Scientometrics, 61(2), 253-270.

Gauffriau, M., Larsen, P.O., Maye, I., Roulin-Perriard, A., \& Ins, M. (2008). Comparisons of results of publication counting using different methods. Scientometrics, 77(1), 147-176.

Gibbs, W.W. (1995). Lost science in the Third World. Scientific American, 273, 92-99.

Glänzel, W. (2001). National characteristics in international scientific coauthorship relations. Scientometrics, 51(1), 69-115.

Glänzel, W., \& Schubert, A. (2001). Double effort = Double impact? A critical view at international co-authorship in chemistry. Scientometrics, 50(2), 199-214.

Glänzel, W., Schubert, A., \& Czerwon, H. (1999). A bibliometric analysis of international scientific cooperation of the European Union (1985-1995). Scientometrics, 45(2), 185-202.

Guan, J., \& Ma, N. (2004). A comparative study of research performance in computer science. Scientometrics, 61(3), 339-359.

Hofer, E.C., Mckee, S., Birnholtz, J.P., \& Avery, P. (2008). High-energy physics: The Large Hadron Collider collaborations. In G.M. Olson, A. Zimmerman, \& N. Bos (Eds.), Scientific collaboration on the Internet (pp. 143-151). Cambridge, MA: The MIT Press.

Huang, M.H., \& Lin, C.S. (2010). International collaboration and counting inflation in the assessment of national research productivity. In A. Grove (Ed.), Proceedings of the 73rd ASIS\&T Annual Meeting, Retrieved from http://www.asis.org/asist2010/proceedings/proceedings/ASIST_AM10/ openpage.html

Inzelt, A., Schubert, A., \& Schubert, M. (2009). Incremental citation impact due to international co-authorship in Hungarian higher education institutions. Scientometrics, 78(1), 37-43.

Kao, C. (2009). The authorship and country spread of operation research journals. Scientometrics, 78(3), 397-407.

Kim, M.J. (2001). A bibliometric analysis of physics publications in Korea, 1994-1998. Scientometrics, 50(3), 503-521.

King, D.A. (2004). The scientific impact of nations. Nature, 430(6997), 311-316.

Kumari, G. (2009). Synthetic organic chemistry research: Analysis by scientometric indicators. Scientometrics, 80(3), 559-570.
Larivière, V., Gingras, Y., \& Archambault, É. (2009). The decline in the concentration of citations, 1900-2007. Journal of the American Society for Information Science and Technology, 60(4), 858-862.

Leta, J., \& Chaimovich, H. (2002). Recognition and international collaboration: The Brazilian case. Scientometrics, 53(3), 325-335.

Leydesdorff, L. (2000). Is the European Union becoming a single publication system? Scientometrics, 47(2), 265-280.

Leydesdorff, L., \& Wagner, C.S. (2008). International collaboration in science and the formation of a core group. Journal of Informetrics, 2(4), 317-325.

Leydesdorff, L., \& Zhou, P. (2005). Are the contributions of China and Korea upsetting the world system of science? Scientometrics, 63(3), 617-630.

May, R.M. (1997). The scientific wealth of nations. Science, 275(5301), 793-793.

Narin, F., Stevens, K., \& Whitlow, E. (1991). Scientific co-operation in Europe and the citation of multinationally authored papers. Scientometrics, 21(3), 313-323.

Narin, F., \& Whitlow, E.S. (1990). Measurement of scientific cooperation and co-authorship in EC-related areas of science. EC-Report EUR 12900.

New, M.E.J. (2001). Scientific collaboration networks. I. Network construction and fundamental results. Physical Review E, 64, 016131-1-016131-8.

Olson, G.M., Zimmerman, A., \& Bos, N. (Eds.). (2008). Scientific collaboration on the internet. Cambridge, MA: MIT Press.

Pravdić, N., \& Oluić-Vukovic, V. (1986). Dual approach to multiple authorship in the study of collaboration/ scientific output relationship. Scientometrics, 10(5), 259-280.

Pravdić, N., \& Oluić-Vukovic, V. (1991). Distribution of scientific productivity: Ambiguities in the assignment of author rank, Scientometrics, 20(1), 131-144.

Qin, J., Lancaster, F.W., \& Allen, B. (1997). Types and levels of collaboration in interdisciplinary research in the sciences. Journal of the American Society for Information Science, 48(10), 893-916.

Schmoch, U., \& Schubert, T. (2008). Are international co-publications an indicator for quality of scientific research? Scientometrics, 74(3), 361-377.

Thomson Reuters. (2010). Institute for Scientific Information. Retrieve from http://science.thomsonreuters.com/

Van Raan, A. (1998). The influence of international collaboration on the impact of research results. Scientometrics, 42(3), 423-428. 